applied to the lens is being approached, and this is also true of the ciliary body. With the softest variety of rays (half value layers of $0.02 \mathrm{~mm}$. of aluminium), higher doses can be used because the penetration is only about one third of that described above.

$$
\text { F. A. W-N. }
$$

(5) Hicks, Avery M. (San Francisco).-Congenital paralysis of lateral rotators of eyes with paralysis of muscles of face. Arch. of Ophthal., Vol. XXX, No. 1, p. 38, July, 1943.

(5) This condition, although first observed by von Graefe in 1875 , is generally known as Möbiu's syndrome, because of his exact and detailed description of the disease in 1888 and 1892 . Both eyes are affected and the principal symptoms are total paralysis of all four lateral rotator muscles or total paralysis of the abductors, with paresis of the adductors, the latter acting better in convergence than in associated lateral movements. Both facial nerves are also paralysed, either completely or partially, one side being frequently more affected than its fellow. Other congenital defects often accompany this anomaly.

The condition is probably not so uncommon as supposed, Hicks having seen no fewer than four cases of it. The first showed total paralysis of all the muscles of the face, total absence of associated lateral movements of the eyes and a weakness of convergence. The second case differed from the first in that the eyes were convergent and more or less fixed at the internal canthi; also the patient was deaf and had a supernumerary thumb and web fingers. In the third case, the facial nerve retained a few active fibres, while in the fourth, in addition to marked limitation of lateral movements; the vertical movements of the eyes also showed some restriction.

Up-to-date there appears to have been only one autopsy on a case of Möbiu's syndrome, which disclosed marked defects in the motor ganglia and nerve fibres of the medulla and pons. There were no signs of degeneration or of inflammation, and the changes were therefore ascribed to hypoplasia.

F. A. W-N.

\title{
CORRESPONDENCE
}

\section{SILENT SINUSITIS}

To the Editors of THE BRITISH JouRnal of OPHTHALMOLOGY.

DEAR Sirs, - I feel that the article by Miss Rosa Ford (Vol. XXVII, p. 469) on "Iridocyclitis and Choroiditis due to silent sinusitis" should not be allowed to pass without comment. 
In previous correspondence (Brit. Jl. Ophthal., May and June, 1942), I have ventured to criticise her contention that silent sinusitis might be responsible for "retrobulbar neuritis," by showing that silent sinusitis probably does not exist; that the cases reported were unfairly labelled retrobulbar neuritis; and that in any event there was little evidence, if any, connecting the two conditions.

These eriticisms have not been answered; but Miss Ford now shifts her ground slightly and invites us to consider five cases of uveitis in only three of which she herself claims that silent sinusitis was present. I suggest that no useful purpose is served by publishing a succession of ambiguous cases without some attempt to lend verisimilitude to these "bald and unconvincing" narratives; . she must first give us some valid reasons for supposing silent sinusitis to exist before discussing its effects; and secondly, she must show some probable connection between the cause and the eff ects.

As far as I can ascertain, this theory of silent sinusitis is founded upon the following evidence :

(1) The absence of any other feasible explanation for the reported disorders (uveitis, chronic headache, retrobulbar neuritis, rheumatoid arthritis).

I do not think it would be generally agreed that Miss Ford can claim to have excluded more orthodox explanations for many of her cases

(2) The absence of all physical signs or radiological evidence of sinusitis. This point is always stressed in her cases, in several of them a succession of eminent rhinologists have concurred in pronouncing the nose entirely normal. This evidence, to say the least, is equivocal.

(3) Contraction of the peripheral visual fields. This is the only positive finding reported before treatment, and it is, in my submission, entirely fallacious. It is almost unconfirmed. It is a physical sign of very doubtful authenticity or value. It is discounted in strong terms by those most expert in perimetry. It is not uncommon to find considerable variation in the peripheral fields of patients unaccustomed to perimetry ; it is not uncommon to find contraction of the visual fields in suggestible patients. Legitimate inferences from visual field changes can be built up only. as Traquair and his co-workers built them up, by the analysis of large numbers of highly skilled and laborious examinations.

(4) Post-therapeutic nasal discharge. In several of her cases much is made of nasal discharge following intranasal medication. At first sight, this appears to be a good argument, but closer inspection of the details which she herself gives shows that the reported facts actually contradict the theory. Thus she refers (Brit. Med. Jl., August 1, 1942), to a p: ofuse flow of blood and mucus " a week after the antrostomy," and (Brit. Jl.Ophthal., 1942), to a mucus discharge which three weeks later contained flakes of mucopus. Surely if a hidden collection of infected material were to be drained, pus would appear immediately, and of the two, the pus would precede the mucus. These facts point much more convincingly to the production of an intranasal infection than to the relief of one.

(5) The relief of symptoms following therapy. This type of evidence is always open to the objection of " post hoc ergo propter hoc," and it is valueless unless it covers a large number of cases. with adequate controls. Before relying on such evidence Miss Ford must submit a sufficiently large number of cases, and must submit evidence of controls. For example, she must submit evidence of the effects of her -treatment on the normal nose. I shall look forward to her demonstration that the " normal" cases are free from silent sinusitis, which will be, on her own showing, a contradiction in terms.

AllaN H. Briggs.

LINCOLN,

October 20, 1943. 